\title{
Age-related Macular Degeneration: Current concepts in pathogenesis and management
}

\section{Tunji S Oluleye}

Vitreo-retinal Unit, Department of Ophthalmology, University College Hospital, Ibadan, Nigeria

\begin{abstract}
Age-related macular degeneration, which was once thought to be a disease mainly found in Caucasian populations in Europe and America, is now also appearing more frequently among non-white populations in the developing world. Ophthalmic practitioners should be aware of this. This paper reviews current concepts in the pathogenesis and management of agerelated macular degeneration as found in Pubmed journals over the past ten years with a view to recommending optimal treatment regimes for African populations.
\end{abstract}

Key words: age-related macular degeneration, pathogenesis, genetics, management, antiVEGF

\section{INTRODUCTION}

Age-related macular degeneration (AMD) is the leading cause of visual impairment among the elderly in the developed world. ${ }^{1}$ The disease was initially thought to be relatively rare in developing countries, ${ }^{2}$ but recent studies have shown that it is more prevalent than earlier believed, particularly in India ${ }^{3}$ and Nigeria. ${ }^{4}$ Age-related macular degeneration is coming up more frequently in clinical studies as an important cause of low vision in the western ${ }^{5,6,7}$ and south eastern ${ }^{8,9}$ parts of Nigeria. There is no accurate database on the prevalence of this disease in developing countries. This is probably due to the paucity of trained vitreoretinal surgeons and the non availability of equipment needed to make an accurate diagnosis of this important cause of low vision and blindness in the aging segments of African populations. As people are living longer due to improved health care, it is expected that the number of persons with the disease will continue to rise.

This review discusses current concepts such as the role of genetics in the aetiopathogenesis of AMD and the use of antiVEGF (vascular endothelial growth factor inhibitors) in its management and its suitability for African patients.

\section{METHODOLOGY}

A Pubmed search was conducted using the Internet. The search was limited to publications within the last ten years. Only studies that discussed pathogenesis and treatment were considered. The review of literature revealed very few studies from Nigeria and these studies only mention AMD as one of the causes of low vision in Nigeria.

\section{Aetiopathogenesis of AMD}

\section{Genetics}

AMD is a multifactorial disease.$^{10}$ Its pathogenesis results from an interplay of genetics, the environment, and behavioural factors. Family-based studies and molecular genetics have consistently shown that complement factor $\mathrm{H}(\mathrm{CFH})$ and LOC387715 genes on chromosome 1 and 10 respectively are important in the pathogenesis of age-related macular degeneration. ${ }^{11,12}$ In complement factor $\mathrm{H}$ polymorphism, histidine is substituted with tyrosine at position 402 on chromosome $1(Y 402 H) .{ }^{12}$ This results in the production of an abnormal variant of complement factor $H$. Under normal conditions, this factor is involved in the inhibition of the alternate pathway of the complement through its ability to bind with C-reactive protein, thereby down regulating inflammation. ${ }^{12}$ The abnormal variant of complement factor $\mathrm{H}$ produced from the defective gene binds sparingly to the $\mathrm{C}$ reactive protein and this results in an increase in inflammation producing RPE damage and drusen formation, which are important stages in the pathogenesis of AMD. ${ }^{13}$ Increased levels of C-reactive proteins are associated with AMD. ${ }^{14}$ The exact role of the LOC387715 gene is still being investigated. It is associated with neovascular AMD. ${ }^{15}$

Environmental factors, such as solar exposure, are also implicated in the aetiopathogenesis of AMD. ${ }^{16}$ The AgeRelated Eye Disease Study (AREDS) ${ }^{17}$ has shown the benefits of nutritional supplements in patients with AMD. Other factors associated with AMD development include, smoking,

${ }^{*}$ Correspondence: Dr Tunji S Oluleye, Vitreo-retinal Unit, Department of Ophthalmology, University College Hospital, Ibadan, Nigeria. 
increasing age, hyperopia, a high body mass index, being Caucasian, hypertension, lens opacity and the presence of large drusens. ${ }^{18}$ The intake of fish is beneficial. ${ }^{19}$

\section{Clinical Presentation}

\section{Classification of $\mathrm{AMD}^{20}$}

The International Classification and Grading System differentiates age-related maculopathy (ARM), which includes all manifestations of age-related macular abnormalities that are not attributable to any other cause except AMD. The late stages of ARM are named age-related macular degeneration (AMD) and these include both 'dry' and 'wet' stages of $\mathrm{AMD}^{20}$

\section{FEATURES}

A defining feature of ARM is the presence of drusen. Drusen are 'discrete whitish-yellow spots ... which are external to the neuroretina or retina pigment epithelium (RPE)'. 'Hard' drusen, however, are not necessarily a feature of ARM, as they may be present in the eyes without ARM. However, ARM will not be diagnosed if there are no drusen or if only small drusen (less than 63 microns) are present.

\section{Features of early stages of ARM}

1. Multiple small drusen and few intermediate drusen (63124 microns in diameter).

2. Areas of hyperpigmentation associated with drusen.

3. Areas of hypopigmentation associated with drusen.

\section{Intermediate ARM}

According to the AREDS report, wherever a number of 'large' drusen (large drusen is defined as $>=125 \mu \mathrm{M}$ ) were present in both eyes, there was a greater risk of development of AMD in either eye, than if the presence of large drusen occurred in only one eye. In the simplified severity scale described in the AREDS report number 18, drusen are considered a risk factor only if an individual drusen is large (defined as $>125 \mu \mathrm{M}$ ). Drusen size is used instead of drusen area, because it is easier to estimate the size using an ophthalmoscope. The figure $125 \mu \mathrm{M}$ was selected because it approximates the size of a normal retinal vein at the disc margin. ${ }^{20}$

The presence of multiple intermediate or any large drusen is considered an intermediate stage of ARM. The report also showed that patients with 'intermediate' drusen, (defined as any drusen $>63 \mu \mathrm{M}$ but $<=125 \mu \mathrm{M}$ ), or many small drusen, had only a $1.3 \%$ chance of developing advanced AMD over 5 years. ${ }^{17}$

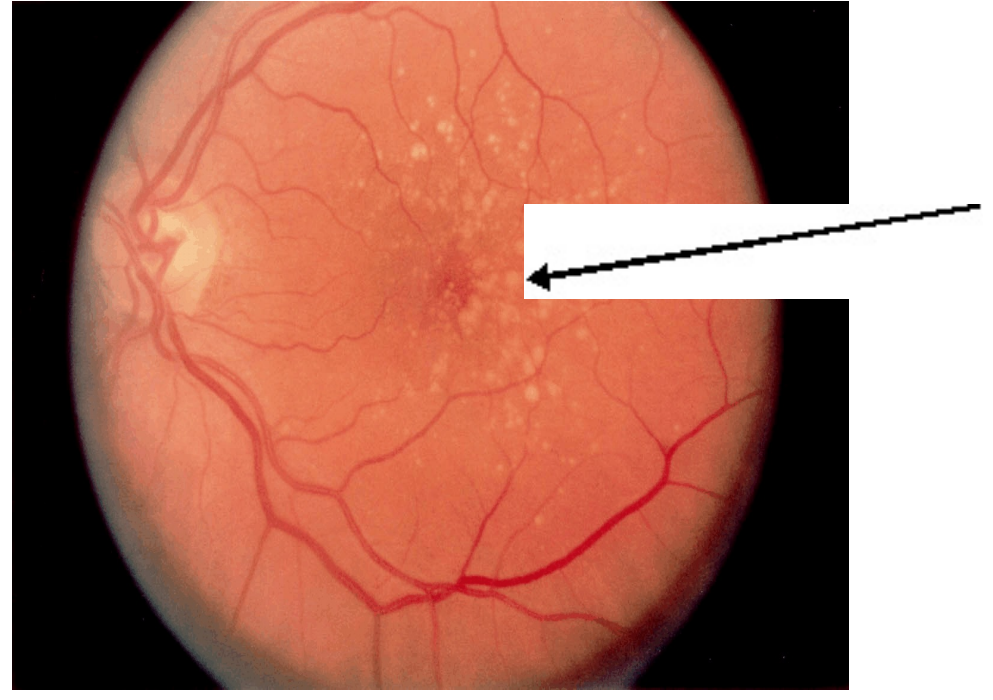

Figure 1. Intermediate ARM with multiple medium to large drusens (from Neil M Bressler MD, Johns Hopkins University School of Medicine).

\section{LATE ARM (AMD)}

\section{Dry AMD (or 'geographic atrophy')}

Dry AMD is characterized by sharply demarcated areas of hypopigmentation in which choroidal vessels (which are at least $175 \mu \mathrm{m}$ in diameter) are more visible than in surrounding areas (see figure 2).

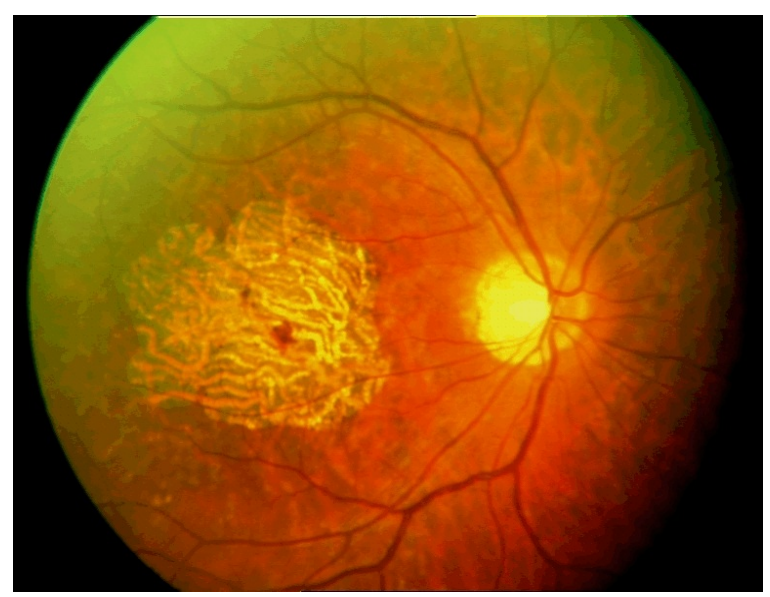

Figure 2. Intermediate ARM with multiple medium to large drusens (from Neil M Bressler MD, Johns Hopkins University School of Medicine).

\section{Wet AMD ('neovascular', 'disciform', or 'exudative'} AMD)

Wet AMD is also associated with the following features:

1. RPE detachments, which may be associated with neurosensory retinal detachment

2. Subretinal or sub-RPE neovascular membranes

3. Epiretinal, intraretinal, subretinal, or subpigment epithelial scar/glial tissue or fibrinlike deposits 
4. Subretinal haemorrhages not related to other retinal vascular disease

5. Hard exudates (lipid) related to other ARM findings but not related to other vascular diseases

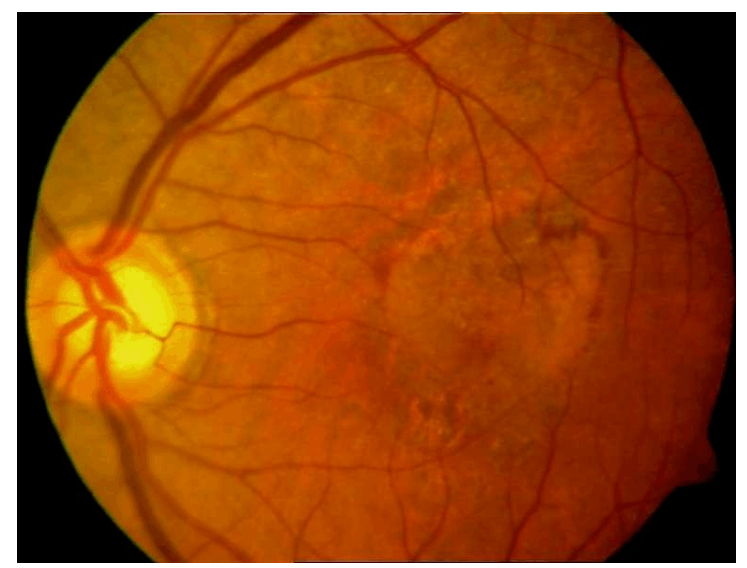

Figure 3. Subretinal neovascular membrane, with subretinal blood (From LV Prasad Eye Institute, Hyderabad, India)

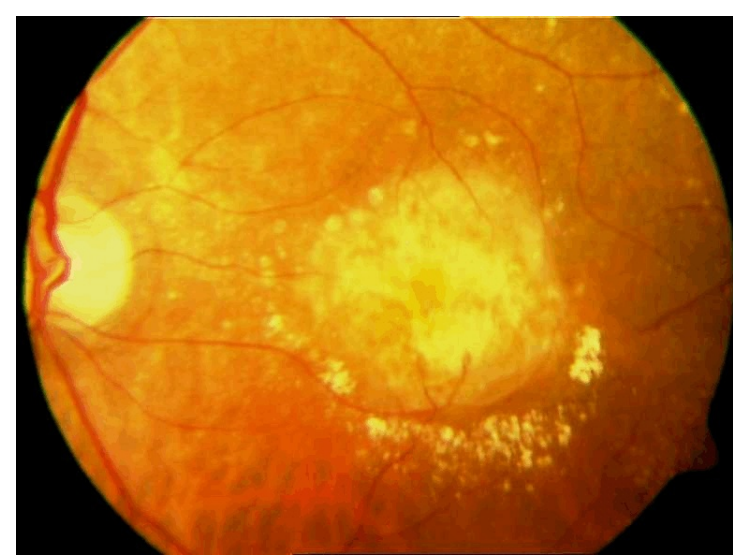

Figure 4. Choroidal neovascular membranes with hard exudates. (From LV Prasad Eye Institute, Hyderabad, India)

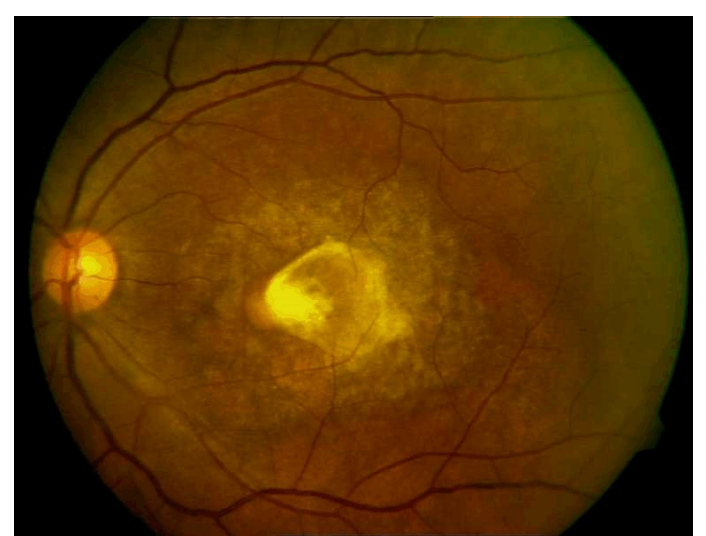

Figure 5. Scarred chroidal neovascular membrane (from LV Prasad Eye Institute, Hyderabad, India)

\section{MANAGEMENT OF AMD}

\section{Investigative procedures}

Slit lamp biomicroscopy. A detailed slit lamp biomicroscopy with a contact (Goldman's 3-mirror lens) or non-contact fundus lens $(+78$ or $+90 \mathrm{D})$ with a bright thin beam is required for detecting choroidal neovascular membranes (CNVM) and fluid due to stereopsis offered by these lenses.

Flourescein angiography. This functional invasive test is an essential tool in making accurate diagnosis of classic and occult choroidal neovascular membranes. Indocyanine angiography(ICG) is useful in detecting occult CNVM especially when blood is blocking fluorescence.

Optical coherence tomography (OCT). Optical coherence tomography is a non invasive investigation that uses the reflection of infrared light to construct the histology section of the posterior pole similar to ultrasonography. It is an excellent tool for patients who are not suitable for flourescein angiography. OCT also helps to define the layers of the retina involved, it detects the presence of retinal oedema, cysts, and neovascular membranes. It also differentiates Type I (sub RPE) from Type II (sub neurosensory retina) CNVM. Patient follow up and education is made easier with OCT.

\section{TREATMENT}

\section{Non-neovascular AMD}

If AMD is at the intermediate stage, patients should be advised to start taking the nutritional/vitamin antioxidant supplements which were found effective in the AREDS study, ${ }^{17}$ provided the individual has not had any adverse reaction to taking any of the components of this formulation.

The antioxidants are taken at a daily dose of:

1. $500 \mathrm{mg}$ of vitamin C

2. 400 International Units of vitamin $E$

3. $5 \mathrm{mg}$ of beta carotene

4. Zinc supplement at a dose of $80 \mathrm{mg}$

5. Cupric oxide at $2 \mathrm{mg}$

Cupric oxide is added to reduce the risk of copper deficiency anaemia associated with taking a zinc supplement. ${ }^{17}$ Cigarette smokers should be warned of the risk of developing lung cancer with a high dose of beta carotene. ${ }^{21}$ Patients with bilateral advanced AMD, but with good vision in at least one eye should also be advised to start taking the above supplements. The AREDS report indicates that the above dietary supplement decreases the risk of vision loss in the eye with advanced AMD with visual acuity of 20/100 or better. ${ }^{17}$ Ophthalmologists in Nigeria should work together with the 
pharmaceutical companies to investigate this vitamin formulation and explore the possibility of making it available as an eye supplement.

\section{Neovascular AMD}

It has been shown that vascular endothelial growth factors (VEGF) play a significant role in the pathogenesis of neovascular AMD. ${ }^{22}$ The new vessels formed can either be within the retinal, sub retinal or sub retinal pigment epithelium (RPE). Although it occurs in only $15 \%$ to $20 \%$ of AMD populations, it more commonly results in severe vision loss compared with non-neovascular AMD. ${ }^{23}$ The origins of these new blood vessels include the choroid (choroidal neovascular membrane (CNVM)) or may start within the retina and proliferate downward, in which case they are called retinal angiomatous proliferation (RAP). Flourescein angiography reveals patterns such as: predominantly classic (clearly defined neovascular network $>50 \%$ of lesion area), occult (poorly defined new vessles), minimally classic (classic $<50 \%$ of lesion area), or predominantly scarred. Bleeding and exudation from these new vessels result in visual loss. The end stage is a fibrotic or disciform scar. ${ }^{23}$

Prior to the year 2000, laser treatment was the standard for classic CNVM. This form of treatment, however, was not satisfactory and sometimes resulted in scotoma formation, especially for lesions close to the fovea. Secondly, neovascularization often recurred at the edges of the laser scar. In 2000, verteporfin photodynamic therapy (PDT) supplanted macular photocoagulation to become the dominant treatment for neovascular AMD. ${ }^{24}$

However, patients receiving PDT still had loss of vision, and the 'benefit' of PDT is measured in terms of decreasing the loss of vision, rather than regaining lost vision. The limitations of PDT have led to more research efforts to find better methods for treating neovascular AMD. Steroids were the next choice of treatment. ${ }^{25}$ Triamcinolone was combined with PDT with improvement or gain in vision. ${ }^{26}$ Complications of intravitreal triamcinolone include cataract formation and glaucoma. This led to the development of angiostatic steroids with no glucocorticoid activity that could inhibit angiogenesis in an in-vitro model. ${ }^{27}$ Anecortave acetate is an angiostatic steroid which is given as a subtenon's injection every 6 months in the treatment of neovascular AMD. It was found to be superior to no treatment ${ }^{28}$ but inferior to PDT. In Nigeria, where PDT is not readily available, the need arises to look for more affordable treatment, such as intravitreal injections.

\section{VASCULAR ENDOTHELIAL FACTOR INHIBITORS (ANTI-VEGF)}

Investigators have shown that VEGF play a significant role in the pathogenesis of neovascular $\mathrm{AMD}_{,}^{22,29-31}$ hence, they are the target of current treatment modalities. In the year 2005, the selective anti-VEGF aptamer pegaptanib (Macugen ${ }^{\mathrm{R}}$ ) showed superiority over available treatment when given intravitreally. ${ }^{31}$ Pegaptanib is an RNA oligonucleotide aptamer that binds with VEGF. About a few months later, the nonselective antiBVEGF bevacizumab (Avastin ${ }^{\mathrm{R}}$ ) molecule also became available. ${ }^{32-34}$ Bevacizumab (Avastin) is a full length antibody against VEGF and a humanized monoclonal antibody synthesized using recombinant DNA technology. ${ }^{35}$

Intravitreal bevacizumab (at a dose of $1.25 \mathrm{mg}$ in $0.05 \mathrm{ml}$ ) has many advantages over all the other treatments discussed so far. First, it seems to lead to an improvement in vision. ${ }^{36}$ Second. it is safe, and third, it is less expensive than PDT or pegaptanib. ${ }^{33}$ Several reports have described its efficacy. ${ }^{36-39}$ In July 2006, ranibizumab (Lucentis ${ }^{\mathrm{R}}$ ) became commercially available in the United States, as the first medication which showed a proven improvement in visual acuity in a randomized controlled trial and was approved by the FDA for the treatment of neovascular AMD. ${ }^{40}$ It is an anti-VEGF antigen-binding antibody fragment (Fab) that is specific for VEGF $_{165}$. Ranibizumab is administered as an intravitreal injection $(0.3 \mathrm{mg}$ or $0.5 \mathrm{mg})$, and it has now been tested in a number of clinical trials for the treatment of neovascular AMD. ${ }^{40,41}$ Two major phase 3 clinical trials for ranibizumab known as the MARINA ${ }^{*}$ and ANCHOR $^{* *}$ have demonstrated superiority of ranibizumab over sham and PDT. ${ }^{42}$

Officials of The National Eye Institute (NEI), USA announced in October 2006 that they will launch their own clinical trials comparing outcomes of both Lucentis and Avastin as macular degeneration treatments. The British Journal of Ophthalmology in July 2006 reported results of one Internet survey among eye doctors who reported no adverse side effects related to the use of Avastin for macular degeneration, seemingly because relatively low doses of the drug are injected into the eye. ${ }^{43}$ But other researchers commenting in the journal pointed out that long-term safety risks of Avastin remain unknown.

In May 2007, the British Journal of Ophthalmology published a cost analysis comparing the two treatments. Researchers concluded that Lucentis, which is about 50 times more expensive than Avastin, would need to be 2.5 times more effective to justify the additional cost. ${ }^{44}$ Research indicates that at present, Avastin appears to be a better buy for the money.

In Nigeria, ophthalmologists should run a randomized trial using bevacizumab; if the results are positive, the

\footnotetext{
"Minimally classic/occult trial of the Anti-VEGF antibody Ranibizumab In the Treatment of Neovascular AMD.

** ANti-VEGF antibody for the treatment of predominantly classic choroidal neovascularization in AMD.
} 
pharmaceuticals could manufacture bevacizumab as a cheaper alternative.

\section{VEGF-trap (Regeneron ${ }^{\mathrm{R}}$ )}

The VEGF-trap consists of an Fc fragment linked to the extracellular portions of the VEGFR1 and VEGFR2 receptors. It is injected intravitreally, where it will bind with free VEGF and prevent activation of VEGF receptors. In-vitro studies are promising. ${ }^{45-46}$

\section{Small inhibitory RNAs (siRNA)}

These are short double stranded RNA molecules that inhibit translation of the native mRNA from which they are derived. In-vitro studies have demonstrated that anti-VEGF siRNAs were able to decrease the expression of the human VEGF gene and appeared to stop the growth of laser induced $\mathrm{CNV}^{47} \mathrm{~A}$ new anti-VEGF siRNA called bevasiranib or Cand5, which is injected intravitreally, is under investigation, and so far, has been shown to be effective. ${ }^{48}$

The International Conference on Age-Related Macular Degeneration, held at Aravind Eye Hospital, India, in January, 2007 recommended the following treatment modality for neovascular AMD.

1. The treatment of extra foveal CNVM is laser treatment.

2. The first line treatment of subfoveal CNVM is intravitreal ranibizumab.

3. Bevacizumab is used when ranibizumab is not available, or when the patient could not afford the cost of ranibizumab.

4. Pegaptanib (Macugen) is considered when the above medications are not available.

5. The only consideration for PDT is when the patient has previously responded well to PDT, or the use of anti-VEGF is contraindicated.

\section{CONCLUSION}

Age-related macular degeneration is no longer a disease confined to developed countries, but occurs throughout the world. Ophthalmologists should carry out careful and detailed evaluations of the macular area in their elderly patients. The recent explosion in research and publications in this area worldwide is an indication of what to expect in the future.

In developing countries like Nigeria, ophthalmologists should work together with the pharmaceutical companies to conduct clinical trials using intravitreal injections, such as bevacizumab to determine the most effective treatment for subfoveal CNVM. Where this is not possible, intravitreal triamcinolone should be investigated, as this is readily available in Nigeria. The most commonly reported side effects of intravitreal injections included red eye (conjunctival haemorrhage), eye pain, small specks in the fields of vision (floaters), increased eye pressure, and inflammation of the eye. Serious side effects, which were rare and often related to the injection procedure, included severe inflammation of the interior of the eye (endophthalmitis), intraocular inflammation, retinal detachment, retinal tear, increased eye pressure, and traumatic cataract. ${ }^{49}$ These complications should be borne in mind when recommending this treatment. Multivitamins in AREDs recommended combinations are available and should be prescribed for patients with the intermediate stage of AMD.

\section{REFERENCES}

1. Congdon N, O'Colmain B, Klaver CC et al. The Eye Diseases Prevalence Research Group. Causes and prevalence of visual impairment among adults in the United States. Arch Ophthalmol 2004; 122: 477B485.

2. Leske MC, Wu SY, Hennis A, Nemesure B, Yan L, Hyman L, Schacht AP. Nine-year incidence of age-related macular degeneration in the Barbados eye studies. Ophthalmology 2006; 113: 29-35.

3. Krishnaiah S, Das T, Nirmalan PK, Nutheti R, et al. Risk factors for for age-related macular degeneration: Findings from the Andhra Pradesh Eye Disease Study in South India. Invest Ophthalmol Vis Sci 2005 Dec; 46: 4442-9.

4. Nwosu SN. Prevalence and pattern of retinal diseases at the Guinness Eye Hospital, Onitsha, Nigeria. Ophthalmic Epidemiol 2000 Mar; 7: 41-8.

5. Adegbehingbe BO, Majengbasan TO. Ocular health status of rural dwellers in south-western Nigeria. Aust J Rural Health 2007; 15: 269-72.

6. Fafowora OF. Prevalence of blindness in a rural ophthalmically underserved Nigerian community. West Afr J Med 1996; 15:22831.

7. Oluleye TS, Ajaiyeoba AI. Retinal diseases in Ibadan. Eye 2006; 20: 1461-3. Epub 2006 Apr 21

8. Ezepue UF Magnitude and causes of blindness and low vision in Anambra State of Nigeria (results of 1992 point prevalence survey). Public Health 1997; 111: 305-9.

9. Nwosu SN. Low vision in persons aged 50 and above in the onchocercal endemic communities of Anambra State, Nigeria. West Afr J Med 2000; 19: 216-9.

10. Haddad S, Chen CA, Santangelo SL, Seddon JM. The genetics of age-related macular degeneration: A review of progress to date. Surv Ophthalmol 2006; 51: 316-363.

11. Gorin MB. A clinician's view of the molecular genetics of agerelated maculopathy. Arch Ophthalmol 2007; 125: 21-29.

12. Klein RJ, Zeiss C, Chew EY, et al. Complement factor $\mathrm{H}$ polymorphism in age-related macular degeneration. Science 2005; 308: 385-389.

13. Moshfeghi M, Blumenkranz M. Role of genetic and 
inflammation in age related macular degeneration. Retina 2007; 27: 269-275.

14. Seddon JM, Gensler G, Milton RC, Klein ML, Rifai N. Association between creactive protein and age-related macular degeneration. JAMA 2004; 291: 704- 710.

15. Shuler K, Hauser M, Caldwell J, Gallins P, et al. Neovascular age-related macular degenerationand its association with LOC387715 and complement factor H polymorphism. Arch Ophthalmol 2007; 125: 63-67.

16. Blumenkranz MS, Russell SR, Robey MG, et al. Risk factors in age-related maculopathy complicated by choroidal neovascularization. Ophthalmology 1986; 93: 552B558.

17. Age-Related Eye Disease Study Research Group. A randomized, placebocontrolled, clinical trial of high-dose supplementation with vitamins $C$ and $E$, beta carotene, and zinc for age-related macular degeneration and vision loss: AREDS report No. 8. Arch Ophthalmol 2001; 119: 1417-1436.

18. Klein R, Peto T, Bird A, Vannewkirk MR. The epidemiology of age-related macular degeneration. Am J Ophthalmol 2004; 137: $486 \mathrm{~B} 495$.

19 Chua B, Flood V, Rochtchina E, et al. Dietary fatty acids and the 5-year incidence of age-related maculopathy. Arch Ophthalmol 2006; 124: 981B986.

20. Bird AC, Bressler NM, Bressler SB, et al. An international classification and grading system for age-related maculopathy and age-related macular degeneration. The International ARM Epidemiological Study Group. Surv Ophthalmol 1995; 39: $367 \mathrm{~B} 374$.

21. The Alpha-tocopherol, Beta Carotene Cancer Prevention Study Group. The effect of vitamin E, and beta carotene on the incidence of lung cancer and other cancers in male smokers. $N$ Eng J Med 1994; 330: 1029-1035.

22. Kvanta A, Algvere PV, Berglin L, et al. Subfoveal fibrovascular membranes in age-related macular degeneration express vascular endothelial growth factor. Invest Ophthalmol Vis Sci 1996; 37: 1929B1934.

23. Seddon JM, Chen CA. Epidemiology of age-related macular degeneration. In: Ryan SJ, ed. The Retina. 4 ed. Philadelphia: Elsevier; 2006:1017B1114.

24. Treatment of Age-related Macular Degeneration with Photodynamic Therapy (TAP) Study Group. Photodynamic therapy of subfoveal choroidal neovascularization in agerelated macular degeneration with verteporfin: One-year results of 2 randomized clinical trials CTAP report. Arch Ophthalmol 1999; 117: 1329B1345.

25. Penfold PL, Wen L, Madigan MC, et al. Triamcinolone acetonide modulates permeability and intercellular adhesion molecule-1 (ICAM-1) expression of the ECV304 cell line: implications for macular degeneration. Clin Exp Immunol 2000; 121: 458.

26. Spaide RF, Soronson J, Maranan L. Photodynamic therapy with verteporfin combined with intravitreal injection of triamcinolone acetonide for choroidal neovascularization. Ophthalmology 2005; 112: 301B304.

27. Crum R, Szabo S, Folkman J. A new class of steroids inhibits angiogenesis in the presence of heparin or a heparin fragment. Science 1985; 230: 1375B1378.

28. The Anecortave Acetate Clinical Study Group. Anecortave acetate as monotherapy for treatment of subfoveal neovascularization in age-related macular degeneration. Ophthalmology 2003; 110: 2372B2385.

29. Lopez PF, Sippy BD, Lambert M, et al. Trans-differentiated retinal pigment epithelial cells are immunoreactive for vascular endothelial growth factor in surgically excised age-related macular degeneration membranes. Invest Ophthalmol Vis Sci 1996; 37: 855B868.

30. Otani A, Takagi H, Oh $\mathrm{H}$, et al. Vascular endothelial growth factor family and receptor expression in human choroidal neovascular membranes. Microvas Res 2002; 64: 162B169.

31. Gragoudas ES, Adamis AP, Cunningham ET, et al. VEGF Inhibition Study in Ocular Neovascularization Clinical Trial Group. Pegaptanib for neovascular age-related macular degeneration. N Engl J Med 2004; 351: 2805B2816.

32. Rosenfeld PJ, Moshfeghi AA, Puliafito CA. Optical coherence tomography findings after an intravitreal injection of bevacizumab (Avastin) for neovascular age-related macular degeneration. Ophthalmic Surg Lasers Imaging 2005; 36: 331 B335.

33. Avery RL, Pieramici DJ, Rabena MD, et al. Intravitreal bevacizumab (Avastin) for neovascular age-related macular degeneration. Ophthalmology 2006; 113: 363B372.

34. Ferrara N, Hillan KJ, Gerber $\mathrm{H}$, et al. Discovery and development of bevacizumab, an anti-VEGF antibody for treating cancer. Nat Rev Drug Discov 2004; 3: 391B400.

35. Ferrara N, Hillan KJ, Novotny W. Bevacizumab (Avastin), a humanized anti-VEGF monoclonal antibody for cancer therapy. Biochem Biophys Res Commun 2005; 333: 328B335.

36. Michels S, Rosenfeld PJ, Puliafito CA, et al. Systemic bevacizumab (Avastin) therapy for neovascular age-related macular degeneration: Twelve-week results of an uncontrolled open-label clinical study. Ophthalmology 2005; 112: 1035 B1047.

37. Avery RL, Pieramici DJ, Rabena MD, et al. Intravitreal bevacizumab (Avastin) for neovascular age-related macular degeneration. Ophthalmology 2006; 113: 363B372.

38. Spaide RF, Laud K, Fine HF, et al. Intravitreal bevacizumab treatment of choroidal neovascularization secondary to agerelated macular degeneration. Retina 2006; 26: 383B390.

39. Rich RM, Rosenfeld PJ, Puliafito CA, et al. Short-term safety and efficacy of intravitreal bevacizumab (Avastin) for neovascular age-related macular degeneration. Retina 2006; 26: 495B511.

40. Preliminary data from phase III trial show Lucentis is the first investigational therapy to demonstrate clinical benefit over visudyne in a head-to-head study of patients with wet AMD. November 7, 2005. Available at:

h t t p : / / w w w.gen e.com / gene / new s / press releases $/$ display.do? method $=$ detail $\& \mathrm{id}=9087 \&$ categoryid $=4$. Accessed June 22, 2006.

41. Genentech granted six-month priority review for Lucentis for the treatment of wet age-related macular degeneration. February 28, 2006. Available at: h t t p : / / w w w.gene.com/gene/news/press- 
releases $/$ display.do method=detail \&id $=9427 \&$ categoryid $=4$. Accessed June 22, 2006

42. Preliminary phase III data from head-to-head study of Lucentis shows Lucentis improved vision compared to visudyne in patients with wet age-related macular degeneration. January 14, 2006. Available at: http://www.gene.com/gene/news/pressreleases $/$ display.do?method=detail\&id=9037. Accessed June 22, 2006.

43. Michels S. Is intravitreal bevacizumab (Avastin) safe? $\mathrm{Br} J$ Ophthalmol 2006; 90: 1333 - 1334.

44. Raftery J, Clegg A, Jones J, Tan SC, Lotery A. Ranibizumab (Lucentis) versus bevacizumab (Avastin): modelling cost effectiveness. Br J Ophthalmol 2007; 91: 1244-6.

45. Aiello LP, Pierce EA, Foley ED, et al. Suppression of retinal neovascularization in vivo by inhibition of vascular endothelial growth factor (VEGF) using soluble VEGF receptor chimeric proteins. Proc Natl Acad Sci USA 1995; 92: 10457B10461.

46. Saishin Y, Saishin Y, Takahashi K, et al. VEGF-TRAP (R1R2) suppresses choroidal neovascularization and VEGF-induced breakdown of blood-retinal barrier. J Cell Physiol 2003; 195: 241B248.

47. Reich SJ, Fosnot J, Kuroki A, et al. Small interfering RNA (siRNA) targeting VEGF effectively inhibits ocular neovascularization in a mouse model. Mol Vis. 2003; 9: 210B216.

48. Acuity Pharmaceuticals reports positive initial phase II results for bevasiranib (CAND5) in wet AMD. June 1, 2006. Available at: http://www.acuitypharma.com/press/release13.pdf. Accessed June 22, 2006.

49. FDA: FDA Consum. 2006; 40: 6. 